\title{
Long-term functional outcomes after bladder exstrophy repair: A single, low-volume centre experience
}

\author{
Ossamah Alsowayan, MD;', John Paul Capolicchio, MD; Roman Jednak, MD;1 Mohamed El-Sherbiny, MD'
}

'Department of Pediatric Surgery, Division of Pediatric Urology, Montreal Children's Hospital and McGill University Health Centre, Montreal, QC, Canada; ${ }^{2}$ Department of Urology, College of Medicine and King Fahd Hospital of the University, University of Dammam, Kingdom of Saudi Arabia

Cite as: Can Urol Assoc J 2016;10(3-4):E94-8. http://dx.doi.org/10.5489/cuai.3104.

\section{Abstract}

Introduction: In this study, we present our experience managing bladder exstrophy (BE) in a low-volume centre over 24 years.

Methods: Charts of patients with BE between 1990 and 2014 were retrospectively reviewed. Patients with $\mathrm{BE}$ closure and $\geq 5$ years followup were included. BE closure was carried out in the first two days of life using either complete primary repair (CPRE) or modernstaged repair (MSRE). Daytime urinary continence (UC) was evaluated by the age of five years. Patients were considered continent if completely dry for $\geq 3$ hours using no or one pad/day. Incontinent patients with bladder capacity $(B C) \geq 100 \mathrm{ml}$ underwent bladder neck reconstruction (BNR) and bilateral ureteric reimplantation (BUR), while patients with $B C<100 \mathrm{ml}$ underwent simultaneous augmentation cystoplasty (ACP).

Results: Sixteen (16) patients met our inclusion criteria with a mean followup time of $18 \pm 5$ years. Ten (10) underwent CPRE, while six underwent MSRE. Four surgeons were involved in patients' management. Two surgeons had previous experience in BE surgery while working in other institutions. Complications included dehiscence in five patients, vesicocutanous fistula in three and breakthrough UTI in eight. Continence was achieved in 15/16 patients: two after BE closure only, seven with BNR, and six who required $\mathrm{ACP}$ and $\mathrm{BNR}$.

Conclusions: Despite the small number of patients and the reterospective nature of the study, some observations are noteworthy. Although continence rate post-primary BE closure was initially low, it rose to $93.8 \%$ after auxiliary continence procedures. This might be at the cost of urethral voiding, which was achieved in $60 \%$ of patients. Our small cohort did not show clear advantage of CPRE vs. MSRE. Our outcomes may not be different from high-volume centres due to the fact that two exstrophy-experienced surgeons performed most primary or subsequent surgeries. For this reason, we recommend assigning designated centres for $\mathrm{BE}$ repair for both new and repeat cases.

\section{Introduction}

Bladder exstrophy (BE) was once a perplexing subject. ${ }^{1}$ Today, with advancement of surgical techniques, improvement of anesthesia, and better understanding of underlying pathology, goals of BE reconstruction started to target far beyond successful anatomical restoration to reach acceptable functional performance in terms of continence, upper tract (UT) preservation, and future sexual function. ${ }^{2}$

In the U.S. and U.K., there are several designated centres for BE repair that receive most new and repeat cases. ${ }^{2}$ Such a system has not been well established in other countries. As such, patients are still being managed in local major health centres, resulting in low volume for each specific centre and interfering with development of adequate experience in the management of this rare condition.

In this study, we present the long-term treatment outcomes of classic BE patients over 24 years in a low exstrophy-volume centre. These cases were mostly managed by two pediatric urologists who gained vast experience in exstrophy surgery while working at other institutions.

\section{Methods}

We retrospectively reviewed charts of patients with classic BE managed at our institution from 1990-2014 who were followed for at least five years post-BE closure.

BE closure was carried out in the first two days of life, with or without osteotomy, using either complete primary repair (CPRE) or modern-staged repair (MSRE) of BE based on surgeon preference. All patients were kept on antibiotic prophylaxis initially and followed up every three months in the first year, every six months in the second year, and yearly thereafter with history, examination, urinalysis, and ultrasonography (US). Voiding cystourethrogram (VCUG) was done at the three-month visit to assess status of vesicoureteric reflux (VUR). Patients with high-grade VUR (G3-5) 
according to the international reflux study grading system, or urinary tract infection (UTI) were maintained on antibiotic prophylaxis. Male patients with epispadias post-MSRE underwent repair by the age of 1.5-2 years.

Daytime urinary continence was evaluated by the age of five years. Patients were considered continent if they were completely dry for $\geq 3$ hours using no or one pad/day. ${ }^{3}$

Bladder capacity (BC) was measured by VCUG until VUR appeared, using uroflowmetry (UFM) data by adding volume of voided urine to residual volume estimated by bladder scan, cystometry, or during cystoscopic examination. Incontinent patients with $B C \geq 100 \mathrm{ml}$ underwent classic Young-Dees-Leadbetter bladder neck reconstruction $(B N R)$ and bilateral ureteric reimplantation (BUR) or bladder neck injection (BNI), while patients with $B C<100 \mathrm{ml}$ underwent simultaneous augmentation cystoplasty (ACP) and Mitrofanoff.

Data were collected and stratified according to type of repair, looking at postoperative complications, UTI, UFM for urethral voiders, continence, and UT status. Sexual function was evaluated when applicable.

Mean \pm standard deviation $(\mathrm{SD})$ was used to describe continuous variables. Fisher exact test was used to compare categorical variables, with $p$ value $<0.05$ considered significant.

\section{Results}

Medical records of 18 patients were reviewed. Sixteen of 18 (seven males, nine females) were eligible for the study. Two patients with $<5$ years followup were excluded. Mean follow up was $18 \pm 5$ years. Because of the long study period, four surgeons were involved in patients' management. Two surgeons had previous experience in BE surgery while working in other institutions.

Of the 16 patients included in the assessment, 10 were reconstructed using CPRE and six using MSRE. None underwent BUR at time of closure. Bladders were maintained dry using ureteric and suprapubic catheters. Seven patients (four female, three male; three post-CPRE, four post-MSRE) required anterior iliac osteotomy at time of closure. All patients were immobilized for three weeks using hip spica cast or mummy wrap.

Surgical complications and outcomes are summarized in Table 1. Dehiscence of the primary closure was observed in five of $16(31.3 \%)$ patients. In one boy who had osteotomy at time of CPRE, reclosure was carried out urgently at age of three weeks. Four patients who were initially closed without osteotomy and immobilized with mummy wrap were reclosed with osteotomy at the age of one year. Three of 16 $(18.8 \%)$ had vesicocutanous fistula, and corrected at a later stage. None of the male patients post-CPRE had corporal loss after the procedure. Eight of $16(50.0 \%)$ had breakthrough
UTI. Two of them required further surgical treatment - laparoscopic nephrectomy in one with poorly functioning kidney and bladder diverticulectomy with BUR in the second.

By the age of five years, only two girls $(12.5 \%)$ were continent, while the remaining 14 patients $(87.5 \%)$ were incontinent. Seven of 14 patients (50.0\%), three male and four female, with $B C \geq 100 \mathrm{ml}$ underwent $B U R$ and $B N R$, or BNI. BNI was done in only one patient post-CPRE with mild incontinence and acceptable BN by cystoscopic exam. Options of BNR vs. BNI were given to the family and they chose BNI. We believe BNI should be offered to patients who have some degree of continence and not soaking wet. ${ }^{4}$ The remaining seven patients, four male and three female, with $\mathrm{BC}<100 \mathrm{ml}$ (three with history of dehiscence) underwent ACP, BNR, BUR, and Mitrofanoff, except one girl, who continued to refuse augmentation.

By the end of followup period, ranging from 10.2-24.6 years, daytime continence was achieved in 15/16 (93.8\%) patients, of whom three patients without ACP required anticholinergic medications. Nine of $15(60.0 \%)$ patients, three male and six female, could void through urethra, while the remaining six patients who had $\mathrm{ACP}$ required clean intermittent catheterization (CIC). Two of $15(13.3 \%)$ continent patients, one $(6.7 \%)$ post-BE closure only, and one $(6.7 \%)$ post-BNR and BUR had nocturnal enuresis.

UFM data at last followup was available for seven of nine patients who void per urethra. Mean Qmax was $13.1 \mathrm{ml} / \mathrm{sec}$; mean average flow $12.3 \mathrm{ml} / \mathrm{sec}$; mean voided volume 164.7 $\mathrm{ml}$, with a mean residual of $47.1 \mathrm{ml}$. The mean residual urine percentage of the whole BC was $18 \%$. Flow curve was bell-shaped in three, flattened in three, and plateau in one.

The mean $\mathrm{BC}$ for patients who underwent BE repair only was $158 \mathrm{ml}$ at mean age of $95 \pm 20$ months. For patients who underwent $B N R$ and $B \cup R$, or $B N I$ the mean $B C$ was 221 $\mathrm{ml}$ at mean age of $116 \pm 30$ months. Patients who underwent $\mathrm{ACP}, \mathrm{BNR}$, and BUR had a mean BC of $445 \pm 122 \mathrm{ml}$ at mean age of $106 \pm 30$ months.

Cystometries were available for seven patients. One of seven was a female post-CPRE only and showed increase in $\mathrm{BC}$ from $61 \mathrm{ml}$ at age one year to $177.7 \mathrm{ml}$ at age six years, with voiding pressure of $61 \mathrm{~cm} / \mathrm{H}_{2} \mathrm{O}$ without any secondary intervention. While four of seven showed small BC of 61 , 49,33 , and $58 \mathrm{ml}$, and voiding pressures of $18,47,39$, and $80 \mathrm{~cm} / \mathrm{H}_{2} \mathrm{O}$, respectively, and underwent $\mathrm{ACP}, \mathrm{BNR}$, and BUR and followup, cystometry was available for the first and second patients and showed increased BC to 430 and $400 \mathrm{ml}$, respectively. Two of seven patients had capacities of 157 and $107 \mathrm{ml}$ with voiding pressures of 25 and $37 \mathrm{~cm} /$ $\mathrm{H}_{2} \mathrm{O}$, respectively, and after BNR and BUR alone, followup cystometry showed that volume increased to $289 \mathrm{ml}$ and remained stable in the second case of $107 \mathrm{ml}$; both were associated with higher voiding pressures of 105 and $41 \mathrm{~cm} /$ $\mathrm{H}_{2} \mathrm{O}$, respectively. 


\begin{tabular}{|c|c|c|}
\hline MSRE (n=6) & CPRE $(n=10)$ & Significance \\
\hline $3 F \& 3 M$ & $6 \mathrm{~F} \& 4 \mathrm{M}$ & NS \\
\hline $2 / 6$ & $3 / 10$ & NS \\
\hline $1 / 6$ & $2 / 10$ & NS \\
\hline $1 / 6$ & $7 / 10$ & NS \\
\hline $0 / 6$ & $2 / 10$ & NS \\
\hline $2 / 6$ & $4 / 10$ & NS \\
\hline $2 / 10$ & $4 / 10$ & NS \\
\hline $4 / 6$ & $5 / 10$ & NS \\
\hline $1 / 6$ & $2 / 10$ & NS \\
\hline $6 / 6$ & $9 / 10^{*}$ & NS \\
\hline $\begin{array}{l}1 \text { mild chordee \& poor ejaculate } \\
1 \text { mild chordee \& normal ejaculate }\end{array}$ & 1 normal & NS \\
\hline 1 normal with successful pregnancy & $\begin{array}{c}1 \text { normal } \\
1 \text { vaginoplasty }\end{array}$ & \\
\hline \multicolumn{3}{|c|}{$\begin{array}{l}\text { *One female patient refused further surgery after BC and remained incontinent; **One kidney lost function in CPRE group and was removed; ***Three patients, two boys (one post-CPRE } \\
\text { and one post-MSRE) and one girl post-CPRE, had unilaterally poorly function kidneys with } 15-18 \% \text { split function. The fourth patient is a female post-MSRE with ACP, BNR, and BUR that } \\
\text { had bilateral kidney scars with a split function of } 62 \% \text { on the right and } 38 \% \text { on the left side; ****Mild chordee did not preclude sexual activity; certain positions are, however, required for } \\
\text { successful penetration . ACP: augmentation cystoplasty; BC: bladder capacity; BE: bladder exstrophy; BNI: bladder neck injection; BNR: bladder neck reconstruction; BUR: bilateral ureteric } \\
\text { reimplantation; CIC: clean intermittent catheterization; CPRE: complete primary repair of bladder exstrophy; MSRE: modern-staged repair of bladder exstrophy; PVR: post-void residual: } \\
\text { UTI: urinary tract infection. }\end{array}$} \\
\hline
\end{tabular}

The final status of the UT, as evaluated by US and dimercaptosuccinic acid (DMSA) scan is depicted in Table 1. Sexual function in six sexually active patients is depicted in Table 1.

\section{Discussion}

There has been always debate in the literature about the percentage of patients with classic BE who could achieve continence and void per urethra in reasonable frequency, as well as empty their bladders almost completely, while maintaining normal UT. ${ }^{3}$

The definition of continence varied in the literature. Herein, we followed the agreement of the majority to consider three hours dry interval in children $\geq 5$ years as a fair and satisfactory dryness period that allows these children to manage most of their daily activities without social embarrassment or abstinence. ${ }^{3}$

Continence rates after BE repair vary widely in the literature. Johns Hopkins experience of 67 male and 41 female patients post-MSRE showed that continence (three-hour dry interval, nighttime dryness and urethral voiding) was achieved in $47 / 67(70.1 \%)$ and $31 / 41(75.6 \%)$ of patients, respectively. Thirteen (13) of 67 (19.4\%) of boys failed BNR and seven of 13 underwent continent diversion, while the remaining six were still incontinent. On the other hand, seven of 41 girls failed $B N R$, four of whom underwent ACP, $B N C$, and Mitrofanoff, while the other three remained incontinent. Their reports lacked data on UT status or urodynamic evaluation. ${ }^{5,6}$

The Seattle group reviewed their prolonged experience of 39 CPRE cases and identified 23/39 (59.0\%) valid for continence evaluation. ${ }^{7}$ Continence was reported in $17 / 23$ (73.9\%) using two-hour dry interval and urethra voiding. This was achieved through CPRE alone in five of $17(29.4 \%)$, BNI in three of $17(17.6 \%)$, BNR in four of 17 (23.5\%), or combined $\mathrm{BNR}$ and $\mathrm{BNI}$ in five of 17 (29.4\%). ACP was needed only in one patient upon view of small BC. CIC was used as an assist to fully evacuate the bladder in four of 17 patients and was used exclusively by one to gain continence. They did not present urodynamic data and the UT status was presented collectively for the whole cohort and was not stratified to show the impact of different combinations, especially in the continent group. Valid renal units available for evaluation were 56, of whom 17 (30.4\%) had no hydronephrosis (HN), 25 (44.6\%) had mild, $10(17.9 \%)$ had moderate, and four $(7.1 \%)$ had severe HN. VUR was managed collectively in $21 / 39$ patients with BUR and in three of 39 patients by Deflux ${ }^{\circledR}$.

Boston experience with regard to continence was available for 21/32 (65.6\%) who underwent CPRE and were older 
than four years. Three of $21(14.3 \%)$ required BNI, while six of $21(28.6 \%)$ required BNR. Dry intervals were $<1$ hour in seven of 21 patients $(33.3 \%), 1-2$ hours in six $(28.6 \%), 2-3$ hours in four (19.0\%) and $>3$ hours in four of $21(19.0 \%)$. None of the patients in their series needed ACP, while two needed $\mathrm{CIC} .{ }^{8}$ Seventeen (17) of 32 required BUR, six after BNR. Of the remaining 15 patients, six had unilateral, six had bilatera, and three didn't have VUR. At the end of their followup period, seven of 32 patients had mild-moderate $\mathrm{HN}$, four bilateral and three unilateral. Nine of 32 patients had pyelonephristis, six with scarring. Urodynamic study (UDS) was available for $27 / 32$ patients. All except one patient had a $\mathrm{BC}<70 \%$ of the predicted value for age. Two of 27 had dertruser overactivity. Simultaneous electromyogram (EMG) was done in 13/27 patients and showed normal synergic sphincter with voiding.

Results of continence after BNR vary extensively in theliterature. Mouriquand et al reported $45 \%$ continence rate of 80 children with BE. ${ }^{9}$ Capolicchio et al reported $94 \%$ continent female compared to $69 \%$ male, flagging the gender impact on results. ${ }^{10}$ In the present report, seven of 16 $(43.8 \%)$, four female and three male, were continent after $\mathrm{BNI}$ or BNR only.

The need for ACP is widely variable between series, reported in $0-70 \%$ of children. This reduces the ability to void spontaneously to about $50 \%$ of children. ${ }^{11}$ In our series, augmented patients (37.5\%) enjoyed bigger BC and a safe UT, but at the cost of need for CIC.

One of the questions still awaiting an answer is how far we can go to achieve the best possible continence while keeping UT safe? It is a management dilemma, which should not overlook other factors, such as each patient and family preferences, motivation, and tolerance to the available options.

The main objective of this study is to find out the outcome of these patients while managed in a low-volume centre and not to directly compare different surgical approaches. The high rate of fistula and dehisce may be explained by the fact that some of the earlier patients in this series were managed initially by adult urologists.

Data from our series showed that continence following successful BE closure only is $12.5 \%$. This increased to 93.8\% after successful $\mathrm{BNI}, \mathrm{BNR}$, or $\mathrm{ACP}$, considering a dry interval of three hours, regardless of the method of voiding. Continence decreased to $60 \%$ if we considered the ability of urethral voiding. Our outcomes may not be different from high-volume centres due to the fact that most primary or subsequent surgical interventions were performed by two surgeons who developed exstrophy experience while working at other institution.

Patients with BE have normal libido compared to the normal population. ${ }^{12}$ Reconstructing the genitalia in a way that allows normal sexual intercourse is a matter of priority. ${ }^{13}$
Short penis, chordee, and poor ejaculation quality are the most common complaints faced in clinical practice.

In this series, six of $16(37.5 \%)$ were sexually active, three male and three female. Of the male patients, two had mild chordee and unconventional position for successful penetration, while one had poor ejaculation. Of the female patients, one required vaginoplasty because of stenosed vaginal introitus, while the other two had normal sexual activity, one with successful pregnancy.

The main restriction to our work is the small number of cases, lack of complete documentation of some variables (such as bladder plate size), and the retrospective nature. Although only few centres around the world are able to recruit enough cases to generate reportable conclusions, there is still room for smaller series to probe debatable issues. There is generally a lack of prospective studies on $\mathrm{BE}$ in the literature, therefore, retrospective ones are still the most used reporting tool.

\section{Conclusion}

Despite the small number of patients and the reterospective nature of the study, some observations are noteworthy. Continence following successful BE closure only is low at $12.5 \%$. An auxiliary continence procedure to achieve continence seems to be inevitable. Continence rate after successful auxiliary procedure rose to $93.8 \%$. This might be at the cost of urethral voiding, which was achieved in $60 \%$. Our outcomes may not be different from high-volume centres due to the fact that most primary or subsequent surgical interventions were performed by two exstrophy-experienced surgeons. For this reason, we recommend assigning designated centres for $\mathrm{BE}$ repair that receive most new and repeat cases.

Competing interests: The authors declare no competing financial or personal interests.

This paper has been peer-reviewed.

\section{References}

1. Ezell WW, Carlson HE. A realistic look at exstrophy of the bladder. Br J Urol 1970;42:197-202. http:// dx.doi.org/10.1111/i.1464-410X.1970.tb10022.x

2. Nelson CP, Dunn RL, Wei JT, et al. Surgical repair of bladder exstrophy in the modern era: Contemporary practice patterns and the role of hospital case volume. J Urol 2005 174:1099-102. http://dx.doi. org/10.1097/01.ju.0000169132.14799.33

3. Lloyd IC, Spano SM, Ross SS, et al. How dry is dry? A review of definitions of continence in the contemporary exstrophy/epispadias literature. J Urol 2012;188:1900-4. http://dx.doi.org/10.1016/i. juro.2012.07.017

4. Shah BB, Massanyi EZ, Dicarlo H,et al. Role of urethral bulking agents in epispadias-exstrophy complex patients. J Pediatr Urol 2014;10:176-80. http://dx.doi.org/10.1016/i.jpurol.2013.08.004

5. Baird AD, Nelson CP, Gearhart JP. Modern staged repair of bladder exstrophy: A contemporary series. J Pediatr Urol 2007;3:31 1-5. http://dx.doi.org/10.1016/i.jpurol.2006.09.009 
Alsowayan et al.

6. Purves JT, Baird AD, Gearhart JP. The modern staged repair of bladder exstrophy in the female: A contemporary series. J Pediatr Urol 2008;4:150-3. http://dx.doi.org/10.1016/i.jpurol.2007.08.003

7. Shnorhavorian $M$, Grady RW, Andersen $A$, et al. Long-term followup of complete primary repair of exstrophy: The Seattle experience. J Urol 2008;180:1615-9; discussion 1619-20. http://dx.doi.org/10.1016/i. juro.2008.04.085

8. Gargollo PC, Borer JG, Diamond DA, et al. Prospective followup in patients after complete primary repair of bladder exstrophy. J Urol 2008;180:1665-70; discussion 1670.

9. Mouriquand PD, Bubani T, Feyaerts A, et al. Long-term results of bladder neck reconstruction for incontinence in children with classical bladder exstrophy or incontinent epispadias. BJU Int 2003:92:997-1001; discussion 1002. htrp://dx.doi.org/10.1111/i.1464-410X.2003.04518.x

10. Capolicchio $G$, Mclorie $G A$, Farhat $W$, et al. A population-based analysis of continence outcomes and bladder exstrophy. J Urol 2001;165:2418-21. http://dx.doi.org/10.1016/S0022-5347(05)66218-0
11. Woodhouse CR, North AC, Gearhart JP. Standing the test of time: Long-term outcome of reconstruction of the exstrophy bladder. World J Urol 2006; 24(3):244-9. http://dx.doi.org/10.1007/s00345006-0053-7

12. Woodhouse CR. Sexual function in boys born with exstrophy, myelomeningocele, and micropenis. Urology 1998;52:3-11. http://dx.doi.org/10.1016/S0090-4295(98)00121-6

13. Stein R, Hohenfellner $K$, Fisch $M$, et al. Social integration, sexual behaviour and fertility in patients with bladder exstrophy: A long-term followup. Eur J Pediatr 1996; 155:678-83.

Correspondence: Dr. Ossamah Alsowayan, Department of Urology, College of Medicine and King Fahd Hospital of the University, University of Dammam, Saudi Arabia; sowayan81@gmail.com 